\title{
Resiliência na Rua: Um Estudo de Caso ${ }^{1}$
}

\author{
Simone dos Santos Paludo ${ }^{2}$ \\ Silvia Helena Koller \\ Universidade Federal do Rio Grande do Sul
}

\begin{abstract}
RESUMO - Resiliência pode ser entendida como um processo dinâmico envolvendo uma adaptação positiva frente a situações de adversidade significativa. Entretanto, quando focalizado em adolescentes que vivem em situação de rua, resiliência parece inatingível. Este artigo pretende apresentar e discutir as possibilidades e adversidades presentes em suas vidas. Trata-se de um estudo de caso qualitativo com objetivo de descrever o processo de resiliência na trajetória de vida de uma adolescente em situação de rua. Participou desse estudo uma adolescente de 14 anos do sexo feminino. Os fatores de risco e proteção foram analisados nos diferentes níveis propostos pela abordagem ecológica: pessoa, processo, contexto e tempo. Pode-se constatar a presença constante dos riscos na vida da menina, no entanto, destacam-se as características individuais e a rede de apoio como principais fatores de proteção e colaboradores no processo de resiliência.
\end{abstract}

Palavras-chave: resiliência; situação de rua; risco; proteção.

\section{Resilience in Street: A Case Study}

\begin{abstract}
Resilience can be understood as a dynamic process involving positive adaptation in a significant adversity. However, when it focus on adolescents that live in street context, resilience seems unattainable. That article intends to present and to discuss possibilities and adversities in their lives. It is a case study that describes the process of resilience in street situation. An adolescent in street situation, 14 years of age, female participated in it. The risk and protection factors were analyzed in the different levels proposed by the ecological approach: person, process, context and time. Risks permeate their entire live, but individual characteristics and support are main protection factors and they can colaborate with resilience process.
\end{abstract}

Key words: resilience; street situation; risk; protection.

Atualmente tem aumentado o interesse de pesquisadores no estudo da resiliência em populações envolvidas com situações de risco pessoal e social (Cecconello, 2003; Cowan, Cowan \& Schulz, 1996; Hutz, Koller \& Bandeira, 1996; Luthar, 1991; Rutter, 1987, 1993, 1996; Yunes, 2001). A complexidade que envolve o contexto ecológico da vida nas ruas proporciona às crianças e aos adolescentes, que utilizam esse espaço como moradia, o desenvolvimento de diversas influências, ora positivas, ora negativas. Essa perspectiva admite que, em um mesmo contexto ecológico-evolutivo, diferentes caminhos de desenvolvimento podem ser percorridos, tornando-as vulneráveis ou resilientes (Brito, 1999).

Embora a definição de resiliência seja utilizada há muito tempo pela Física e Engenharia, encontra-se, ainda, em fase de construção e debate como construto psicológico. Originariamente, o termo resiliência refere-se à "propriedade pela qual a energia armazenada em corpo deformado é devolvida quando cessa a tensão causadora da deformação elástica" (Ferreira, 1999). Na Psicologia, o estudo desse fenômeno é relativamente recente e vem sendo pesquisado há pouco mais de 20 anos. Segundo Yunes (2003), a definição de resiliência ainda não é clara e nem tão precisa quanto a da

1 Apoio Capes. As autoras agradecem a participação das bolsistas de Iniciação Científica do Grupo de Estudos sobre Emoções Morais e Desenvolvimento em Situação de Risco do CEP-RUA/UFRGS. Este estudo faz parte da Dissertação de Mestrado em Psicologia do Desenvolvimento (UFRGS) da primeira autora, orientada pela segunda autora.

2 Endereço: CEP-RUA/UFRGS, Instituto de Psicologia, Rua Ramiro Barcelos 2600/104, Porto Alegre, RS, Brasil 90035-003. E-mail: cep_rua@ufrgs.br
Física, uma vez que devem ser considerados os fatores e as variáveis que envolvem o seu principal objeto de estudo - os seres humanos. Inicialmente, as pesquisas utilizavam o conceito de invulnerabilidade para definir resiliência, mas esse termo é equivocado, porque denota uma idéia de resistência absoluta a qualquer adversidade e, no entanto, esta não é a realidade (Masten \& Gamerzy, 1985). Resiliência aparece então definida como a habilidade do indivíduo de superar as adversidades (Werner \& Smith, 1992). Resiliência é um conceito extremamente contextual e dinâmico, uma vez que existem vários fatores que podem influenciar nesse processo (Masten, 2001). A resiliência se expressa frente a presença de fatores de risco. Não existirá resiliência sem o risco. O risco tem um potencial para predispor pessoas e populações a resultados negativos e podem estar presentes tanto em características individuais como ambientais (Masten \& Gamerzy, 1985). Entre os fatores de risco individuais encontram-se características como gênero, problemas genéticos, carência de habilidades sociais, intelectuais e características psicológicas limitadas, e os fatores de risco ambientais caracterizam-se por eventos de vida estressantes, ausência de apoio social e afetivo e o baixo nível-sócio econômico.

Tradicionalmente, o conceito de risco tem sido concebido como um fator que predispunha resultados negativos, ou seja, a simples presença de um fator de risco já era suficiente para se prever consequiências indesejáveis (Cowan \& cols., 1996). A vida na rua, por exemplo, é considerado um fator de risco relacionado com as conseqüências negativas para o desenvolvimento saudável de crianças. Atualmente, existe uma visão mais dinâmica, o risco passa a ser visto como 
uma variável vinculada diretamente ao resultado provocado. Assim, pode-se afirmar que a mesma variável provoca resultados diferentes para a mesma pessoa em momentos diferentes do seu desenvolvimento ou, ainda, pode causar determinados resultados a uma pessoa e a outra não. Por exemplo, a rua pode influenciar negativamente no desenvolvimento de uma criança, mas ao mesmo tempo promover nela algumas habilidades. No entanto, para que o fator de risco tenha influência é preciso que o indivíduo esteja fragilizado ou vulnerável diante dele. Vulnerabilidade refere-se a uma predisposição individual para apresentar resultados negativos no desenvolvimento, ou seja, aumenta a probabilidade de um resultado negativo ocorrer na presença de um fator de risco (Masten \& Gamerzy, 1985). Além disso, está relacionada com uma característica pessoal, inata ou adquirida. Contudo, somente na interação com os eventos de vida é que podem ser observadas as manifestações da vulnerabilidade.

Na presença de risco emerge a ação de fatores protetivos. Os fatores de proteção são características que diminuem a probabilidade de um resultado negativo acontecer na presença de um fator de risco, reduzindo a sua incidência e gravidade (Cowan \& cols., 1996). Esses podem modificar os efeitos do risco através da interação com eles. Segundo Gamerzy e Masten (1994), são identificados três grupos considerados fatores de proteção: as características individuais, a coesão familiar e apoio afetivo e o apoio social externo. Os fatores de proteção têm a função de auxiliar o indivíduo a interagir com os eventos de vida e conseguir bons resultados, conseqüentemente, incrementando o processo de resiliência. Resiliência não é, no entanto, uma característica fixa. O fato do indivíduo apresentar resiliência em determinado momento da vida não significa que continuará apresentando ao longo do seu desenvolvimento (Rutter, 1993; Zimmerman \& Arunkumar, 1994). Dessa forma, o estudo da resilência requer uma compreensão dinâmica e interacional dos fatores de risco e de proteção. Além disso, faz-se necessária uma análise ecológica a fim de compreender a maneira como o indivíduo percebe e enfrenta as adversidades, decorrentes dos processos proximais ocorridos entre ele e sua história e rotinas, bem como a influência do contexto e do tempo presente em que está vivendo (Cecconello, 2003).

Diante da descrição de literatura sobre a presença de risco no espaço da rua, o processo de resiliência ainda parece ser algo "inatingível" quando focalizados em crianças e adolescentes que fazem deste o seu espaço de desenvolvimento e socialização. A literatura aponta para as adversidades a que estão expostos, enfatizando as situações de risco físico, social e emocional. Poucos estudos os descrevem como seres humanos em desenvolvimento, que apresentam características psicológicas sadias, apesar das dificuldades impostas pelo ambiente hostil no qual estão inseridos (D'Abreu, Mullis \& Cook, 1999; Koller \& Hutz, 1996; Swart-Kruger \& Donald, 1996).

A literatura é unânime em relação aos fatores de riscos que envolvem a vida dessas crianças e adolescentes. A violência, a ausência de adultos cuidadores, as drogas, os perigos e a falta de cuidados básicos são desafios constantes e tornam essa população extremamente vulnerável. Por outro lado, o enfrentamento dessas adversidades e a utilização de estratégias adequadas para lidar com essas situações promovem a construção do processo de resiliência. Devido à complexidade que envolve a vida cotidiana dessas crianças, este estudo investigou os fatores de proteção e de risco presentes na vida de uma menina em situação de rua. A Abordagem Ecológica do Desenvolvimento Humano, proposta por Urie Bronfenbrenner (1979/1996, 1995, 2005; Bronfenbrenner \& Morris, 1998), ressignifica o fenômeno da vida na rua e possibilita um novo olhar sobre essa importante questão. Estudos ecológicos privilegiam uma visão contextualizada da situação e dos processos de interação desta adolescente, em situação de rua, com descrição de eventos típicos da vida na rua, fatores de risco extremos a serem enfrentados por uma criança e a expressão de sua luta e estratégias de superação das adversidades. Através da inserção ecológica, os pesquisadores estão presentes no ambiente natural, e focalizam a amplitude do viver na rua. A criança e a sua interação com a rua deixam de ser apenas sujeito e produto da exclusão, e tornam-se extremamente significativas para o entendimento global da sua própria história, da vida na rua e o seu desenvolvimento. Assim, pode-se reafirmar a posição de Bronfenbrenner (1999) sobre a ocorrência de um fenômeno dentro do espaço ecológico, como sendo, ao mesmo tempo um produto e um produtor de mudança evolutiva (Paludo \& Koller, 2004).

De maneira geral, os estudos ecológicos valorizam a identificação de aspectos evolutivos saudáveis e a compreensão do desenvolvimento através da interação das variáveis: processo, pessoa, tempo e contexto (Alves, 2002). No caso das crianças em situação de rua, essa abordagem redefine e reinterpreta as possibilidades de desenvolvimento humano no contexto de rua, substituindo a imagem estereotipada de crianças que possuem déficit intelectual, moral, emocional, social e físico pela visão contextualizada, privilegiando os aspectos saudáveis e identificando o processo dinâmico de resiliência (Santos, 2004; Neiva-Silva, 2003; Paludo, 2004; Santana, 2003). Assim, este artigo pretende apresentar e discutir o processo de resiliência de uma menina em situação de rua.

\section{Método}

Este trata de um estudo de caso qualitativo com o objetivo de descrever os contextos nos quais a menina está inserida, analisando os fatores de risco e proteção existentes nesse ambiente que colaboraram e/ou interferiram no processo de resiliência. Participou deste estudo uma adolescente, com 14 anos de idade, do sexo feminino, identificada como menina em situação de rua através de características exteriores, tais como, a aparência, a vinculação com a família, a atividade exercida, o local em que se encontra e a ausência de um adulto responsável junto à mesma (Neiva-Silva \& Koller, 2002).

Os estudos realizados com essa população possuem algumas particularidades em relação aos procedimentos de coleta de dados. Assim, o presente estudo baseia-se nas preocupações éticas e metodológicas discutidas nas recentes pesquisas envolvendo as crianças e adolescentes em situação de rua do Centro de Estudos Psicológicos de Meninos e Meninas de rua (Alves, 1998; Alves, 2002; Paludo \& Koller, 2004). As questões éticas na pesquisa envolvendo seres humanos foram amplamente discutidas e incorporadas a esta pesquisa com 
base na Resolução nº196 (Ministério da Saúde, 1996) e a n ${ }^{\circ}$ 016 (Conselho Federal de Psicologia, 2000). A Resolução 196 consiste em diretrizes e normas que regulam as pesquisas com os seres humanos, pelas quais estas devem atender às exigências éticas e científicas, caracterizadas pelo consentimento livre e esclarecido, a ponderação entre os riscos e os benefícios e a relevância social da pesquisa. A Resolução $n^{\circ}$ 016 favoreceu importantes avanços, assegurando o bem-estar e saúde dos participantes. Uma importante colaboração da Resolução $n^{\circ} 016$ refere-se à pesquisa com as populações consideradas em situação de risco, uma vez que, não exigem o consentimento informado de pais que não tenham contato sistemático com os seus filhos, guardiões legais que não tenham condições cognitivas para avaliar as conseqüências da participação das crianças na pesquisa e, ainda, pais ou guardiões que tenham abusado, negligenciado ou sido coniventes com o abuso de seus filhos.

No presente estudo foi respeitada a decisão da adolescente sobre a sua participação frente à apresentação clara dos objetivos e procedimentos da mesma. Ressaltou-se, ainda, a garantia de sigilo e proteção à adolescente e à entrevistadora. Cabe à entrevistadora respeitar os direitos da criança e evitar expô-la a situações que potencializem seus riscos. Devido à situação de rua, à falta de atendimento às necessidades básicas e às características dessas crianças e adolescentes não foi fornecido nenhum tipo de recompensa como gratificação à participação na pesquisa, uma vez que essa atitude impossibilitaria a escolha e seria um atrativo para várias participações. Outras formas de assistência foram disponibilizadas, como o fornecimento de referências de serviços sociais e instituições.

Crianças e adolescentes fazem uso intermitente da rua e das instituições de atendimento (Santana, 2003). De acordo com essas considerações, a coleta de dados foi realizada em uma Casa de Acolhimento da cidade de Porto Alegre, a qual atende crianças e adolescentes em situação de risco pessoal e social. A proposta bioecológica de investigação por observação naturalística privilegiou a inserção ecológica da pesquisadora no ambiente a ser estudado. Esse primeiro contato foi extremamente importante para o estabelecimento de confiança e empatia, e conseqüentemente, para a realização da entrevista. Os objetivos do estudo foram explicados da forma mais simples possível, utilizando-se de vocabulário coloquial. A adolescente que se voluntariou foi acompanhada através de observações, conversas informais e após, foi realizada uma entrevista semi-estruturada com o objetivo de coletar dados biosociodemográficos e a história de vida da menina. Devido à presença intensa de ruídos e outras crianças e adolescentes na Casa de Acolhimento, a entrevistadora e a menina escolheram um lugar adequado, cômodo e seguro para a realização da entrevista. Uma vez aceita a participação na pesquisa e a utilização do gravador, foi iniciada a coleta de dados. A entrevistadora esteve atenta a situações que poderiam prejudicar o desempenho ou a atenção da entrevistada, entre esses, o uso de substâncias psicoativas, a aproximação ou presença de monitores e outras pessoas presentes, eventos e atividades locais, etc.

A entrevista semi-estruturada obedeceu a uma sequiência, envolvendo dados sociodemográficos e ecológicos. Os relatos, certamente, envolveram sentimentos e conteúdos emocionalmente mobilizadores, e para isso, a entrevistadora esteve atenta e teve uma atitude empática e disponível para abordar as questões trazidas à tona. A entrevista foi gravada e transcrita posteriormente para facilitar a análise. A análise de conteúdo (Bardin, 1977/1979) permitiu identificar os fatores de risco e proteção, bem como os contextos que permeiam a trajetória da adolescente. Para o entendimento e a discussão dos achados foi utilizada a perspectiva ecológica (Bronfenbrenner, 1979/1996), a qual permite identificar e avaliar aspectos evolutivos relacionados ao contexto, processo, tempo e as características da pessoa.

\section{Resultados}

Primeiramente, será apresentada uma descrição do caso a fim de explicitar a trajetória de vida da menina. É importante salientar que os dados apresentados referem-se à percepção da menina sobre sua própria vida. Os fatores de risco e proteção serão apontados e discutidos nos diferentes níveis propostos pela abordagem ecológica. Serão identificadas no nível pessoa as principais características individuais que colaboraram para a construção do processo de resiliência da menina. Em relação ao nível processo, serão discutidos a coesão institucional e as estratégias de superação nos diferentes contextos (microssistema, messosistema, exossistema e macrossistema). Além disso, será enfatizada a história de vida passada e cotidiana referentes ao nível ecológico do tempo.

\section{Descrição do caso}

Bianca $^{3}$ tem 14 anos, é do sexo feminino, da raça negra, foi abandonada, segundo ela, pela mãe aos seis meses de idade, e até hoje não conhece ninguém de sua família. Durante a infância morou em instituições de abrigo, onde conheceu sua melhor amiga. Sempre teve um bom vínculo com os monitores de lá, mas após presenciar situações de violência realizadas pelas meninas moradoras do abrigo, fugiu com sua amiga Joana. Bianca relatou que Luciana, uma menina mais velha, também moradora do abrigo, bateu na sua amiga e depois introduziu um cabo de vassoura na vagina de Joana, que teve que ser levada ao pronto socorro. Esse evento foi motivador para fuga do abrigo. Elas moraram juntas na rua durante três meses, até o falecimento da menina. Segundo Bianca, elas estavam tomando banho no rio com outras meninas moradoras da rua, até que sua amiga começou a se afogar, elas tentaram socorrê-la fazendo uma corrente para puxá-la, mas não tinham força suficiente. Pediram ajuda a Luciana, que estava presente no local, embora houvesse machucado Joana, teria mais força para puxar a menina. No entanto, ela disse que não ajudaria e desejava que a menina morresse. Após esse acontecimento, Bianca permaneceu na rua durante algum tempo. Foi levada a diversas instituições pelo Conselho, mas não permanecia. Embora não estive vinculada às instituições, nunca deixou de freqüentar a escola, está na oitava série. Iniciou o uso de drogas (loló, maconha, cocaína, álcool, cigarro, crack). Utilizava drogas junto com

3 Todos os nomes relatados no caso são fictícios. 
o namorado e os amigos. Atualmente, utiliza os serviços de diferentes instituições de acolhimento, uma vez que está esperando a decisão judicial para sua internação em uma instituição de abrigo. É uma dependente química em recuperação e monitora de um grupo de dependentes. Pretende fazer faculdade de Direito para ajudar pessoas como ela. Embora Joana tenha relatado eventos e situações bastante difíceis na sua vida devido à sua exposição a diferentes locais, muitas vezes permeados de situações de risco, não culpa e também não julga a atitude da mãe de abandoná-la quando bebê. Acredita no amor de sua mãe, possui uma imagem extremamente positiva e idealizada da mãe que incrementa seu processo de resiliência.

\section{Identificando os fatores de risco e proteção na trajetória de Bianca}

Neste estudo, Bianca foi analisada em sua totalidade, com seus sentimentos, histórias de vida, experiências, crenças, estratégias de sobrevivência e, especialmente, como um ser humano em desenvolvimento. A alegria, a persistência e a espontaneidade são as suas principais características neste momento de vida. Suas crenças a respeito do abandono, da figura materna e das expectativas futuras ressaltam no seu discurso e são vitais no decorrer da sua história de vida. A sua capacidade de superação de adversidades está intrinsecamente relacionada a essas crenças.

O modelo bioecológico (Bronfenbrenner, 1999) privilegia a compreensão do ser humano de maneira ampla e sistêmica. Assim, a adolescente, antes "rotulada" apenas como uma menina em situação de rua, começa a ser entendida como uma pessoa em interação com seu sistema ecológico. O modelo bioecológico destaca o processo proximal como o principal mecanismo responsável pelo desenvolvimento, o qual pode ser definido como um processo de interação recíproca mais complexa de um ser humano com as pessoas, objetos e símbolos presentes no seu ambiente imediato (Bronfenbrenner \& Morris, 1998). Outro componente importante é a pessoa. As características da pessoa são vistas tanto como produtoras como produtos do desenvolvimento, pois influenciam nos processos proximais e, ao mesmo tempo, são resultado da interação conjunta destes elementos - processo, pessoa, contexto e tempo (Bronfenbrenner, 1999). Devido à trajetória de Bianca, será priorizada a análise dos quatro níveis ambientais que compõem o contexto, denominados como microssistema, mesossistema, exossistema e macrossistema integrados ao perspectiva do tempo.

De acordo com o relato da adolescente, podem ser enumerados diversos fatores de risco que permearam e ainda continuam presentes na vida da adolescente. A existência de situações "especiais" ao longo do desenvolvimento como, por exemplo, o abandono da mãe, perda da amiga, o vínculo com as instituições entre outros, sejam essas de risco ou não, é uma variável a mais para ser considerada no processo, mas nem sempre é a única ou a mais importante. Dentro da perspectiva ecológica, essas precisam ser descritas e compreendidas no tempo e no contexto. O primeiro aspecto considerado um fator de risco e que desencadeia a presença constante de riscos na trajetória de vida de Bianca refere-se ao abandono e a ausência da rede familiar “... desde os seis meses eu tô em abrigo, não conheci ninguém da minha família...”. Pesquisas identificam a situação econômica precária como principal justificativa do abandono, são encontradas variações apenas referentes aos motivos, as causas e as atitudes das mães frente a essa escolha (Santos, 2004; Weber, 2000). A literatura é unânime em relação ao impacto negativo sobre o desenvolvimento da criança abandonada (Mitchell, 2001, Roig \& Ochtorena, 1993; Weber \& Gagno, 1995). Considerando esses fatores, o abandono pode ser interpretado como um episódio dramático e sofrido na vida de qualquer ser humano No entanto, como poderia ser explicado o desenvolvimento posterior saudável de uma criança que foi abandonada aos seis meses de idade? Provavelmente, vários significados e interpretações podem ser oferecidos para compreensão desse momento de abandono. No caso da Bianca, a sua percepção ou fantasias relacionadas às circunstâncias que levaram a mãe a separar-se dela a auxiliaram e, ainda, facilitam o processo de construção de identidade e de reorganização de sua vida cotidiana. Seu relato sobre a figura da mãe indica essa capacidade de reconstrução:

Eu não sei nada sobre ela, me disseram que o nome dela é Débora. Eu não sei por que ela (mãe) me deixou, entende, eu não vou julgar ela pelo negócio que eu não sei. Talvez ela teve que fazer isso pra alguma coisa, algum negócio. Tenho certeza de que ela achou que estava fazendo o melhor pra mim... Posso não saber nada, mas tenho certeza de que a minha mãe me ama..

É possível que essa relação emocional com a mãe tenha sido significativa, uma vez que garante segurança psicológica até hoje. Bianca se mostra competente e segura na forma de interagir com eventos de vida e relacionamentos interpessoais, é capaz de acreditar em suas potencialidades e demonstrar sentimentos positivos em relação a si mesma e aos outros. Embora o tempo de interação da mãe e filha tenha sido restrito aos seis primeiros meses de vida, parece ter sido tempo suficiente para o desenvolvimento de segurança da menina.

No abandono total, Bianca não só vivencia o caráter definitivo do abandono, como também, enfrenta as perdas secundárias. Ou seja, perde contato com todas as figuras afetivas de referência, o espaço físico familiar, a rotina e, até mesmo, os hábitos da família de origem. Nesta condição, Bianca não só é privada de relacionamentos importantes e cruciais para o desenvolvimento saudável, mas também de todos os parâmetros conhecidos como familiares. A família é a rede primária de apoio para Bianca, independente de sua configuração e dinâmica, é a partir desse núcleo que a criança estabelece relacionamentos de apego com as figuras significativas. O abandono foi um evento significativo na vida desta adolescente marcada por perdas. Entretanto, ela encontrou uma rede de apoio seguro no abrigo que morou durante a sua infância, vinculando-se de forma positiva aos monitores e às crianças que, também, moravam lá como pode-se confirmar em seu relato, “...eu gostava da tias de lá, tinha uma amiguinha, a Joana, eu sei lá eu considerava ela uma irmã para mim, sabe...”. O estabelecimento de sólidos vínculos com a instituição proporciona apoio, capaz de amenizar condições hostis que Bianca enfrentou. 
A instituição pode ser percebida como um importante microssistema estabelecido por Bianca. Segundo Bronfenbrenner (1979/1996), microssistema é definido como um padrão de atividades, papéis e relações interpessoais experenciados pela pessoa em desenvolvimento nos ambientes que ela freqüenta e estabelece relações face a face.

Brito (1999) destacou que as instituições de atendimento, juntamente com seus funcionários, desempenham um importante papel na rede de apoio social e afetivo das crianças. A rede de apoio social tem uma influência profunda na saúde e bem-estar do indivíduo. A família é a primeira e a mais importante, no entanto, o apoio social fora da família corresponde a um fator de proteção para uma variedade de riscos na infância. No caso de Bianca, a rede, constituída pelo abrigo, monitores e amigos, foi essencial para o seu desenvolvimento. Gamerzy e Masten (1994) afirmam que o apoio social proporcionado por amigos, vizinhos, terapeutas, professores, líderes religiosos e outros recursos da comunidade potencializam talentos e habilidades do indivíduo. A rede de apoio social e afetivo pode ser compreendida como um conjunto interligado de recursos pessoais, profissionais e institucionais que venham a oferecer suporte aos adolescentes em situação de risco.

Embora o abrigo tenha exercido um papel essencial de proteção no desenvolvimento de menina, as cenas de violência física que presenciou dentro do abrigo promoveram o desejo de afastamento desse ambiente, conforme seu relato:

Luciana é uma grandona, assim ela é uma baita dum mulherão, bem maior que a gente, nós éramos lá do abrigo, daí a gente sempre brincava junto, daí a Luciana pegou e pediu para as gurias segurarem (a Joana) e enfiou um cabo de vassoura e daí a guria saiu assim toda sangrando, pegou foi pro médico, levou ponto, bem pequeninha ela era.... Me deu raiva daquele lugar, então a gente começou a pensar no que ia fazer para que essas coisas não acontecessem mais.

A violência tem sido definida como ações ou omissões que podem cessar, impedir ou retardar o desenvolvimento pleno dos seres humanos (Koller \& De Antoni, 2004). Ser vítima, testemunha ou agente de violência são condições que podem ser tecidas na história de uma pessoa. No entanto, se uma criança é submetida a situações de abuso haverá um comprometimento em relação ao seu desenvolvimento. As consequiências da violência são diversas. Segundo Kashani e Allan (1998), cada tipo de violência gera prejuízos nas áreas de desenvolvimento: físico, emocional, social, cognitivo e moral. No caso de Bianca, a violência testemunhada desencadeou diversos comportamentos de risco. Primeiramente, a menina fugiu do abrigo e escolheu o ambiente da rua como moradia, provedor de subsistência e espaço de socialização. Este fato pode ser confirmado através de sua fala: "Daí, depois de uma semana, não deu dois meses eu acho, daí a guriazinha queria fugir, ela falou que não queria mais ficar lá, daí eu peguei e fugimos assim...”.

A trajetória da Bianca até chegar definitivamente a morar na rua passa por uma sucessão de fracassos ocorridos na sua interação com a família, instituição, amigos, escola, entre outros (Santana, 2003). A instituição pode ter tanto o potencial de aumentar o risco quanto o de proteger as crianças. Tais experiências contribuem ao expor as crianças a fatores de risco ou a fatores protetivos, estimulando os processos de resiliência e vulnerabilidade. A vivência de eventos traumáticos dentro da instituição promoveu a saída de Bianca para o contexto da rua, ampliando de alguma forma seu mesossistema. Esse elemento consiste no conjunto de microssistemas que uma pessoa freqüenta e nas inter-relações estabelecidas (Bronfenbrenner, 1979/1996). Ele é ampliado sempre que uma pessoa passa a freqüentar e transitar em novos ambientes e assumir diferentes papéis. $\mathrm{O}$ ambiente escolhido pela menina foi a rua.

A vida na rua, muitas vezes, representa a melhor alternativa encontrada pelas crianças que sofrem algum processo de vitimização, seja na família de origem ou na sociedade. Para Bianca e sua amiga, a saída para rua representou uma solução alternativa devido à violência sofrida. Aptekar (1989) afirmou que o afastamento das crianças de um ambiente hostil e estressante, que encontram em casa ou no ambiente onde vivem, pode garantir aspectos de sua saúde mental e revelam habilidades de reorganizar a vida, sugerindo que essas crianças não seriam indivíduos emocionalmente mais frágeis. Koller e Hutz (1996), concordando com o estudo anterior, apontam para os problemas de relacionamento familiar como os principais motivos que levam as crianças à rua. Dessa forma, também, afirmam que o distanciamento desse ambiente pode ser um indicador de saúde mental.

Cada vez mais podem ser observadas crianças e adolescentes "perambulando" pelas ruas da cidade. A migração para esse ambiente tem origem no empobrecimento econômico e afetivo dessas famílias. Essa afirmação é corrobarada em recente estudo realizado pelo Centro Brasileiro de Informações sobre Drogas Psicotrópicas - CEBRID (Noto \& cols., 2003), o qual investigou 2.807 jovens em situação de rua no Brasil. Entre os principais motivos que favorecem a saída de casa estão as dificuldades enfrentadas na família como, por exemplo, conflitos interpessoais, dificuldades financeiras, modificações na estrutura ou ainda o uso de drogas e/ou álcool por algum responsável. No entanto, quando as crianças e os adolescentes saem do ambiente que viviam para o contexto da rua acreditam que estão "livres" de situações semelhantes. A rua, a princípio, oferece a liberdade e a dimensão lúdica que, aos poucos, vai dando lugar às experiências dolorosas da violência física, sexual e moral. Dessa forma, para manter-se na rua, ou desenvolvem estratégias para lidar com essas situações, ou tornam-se vulneráveis. As situações de risco físico, social e emocional podem fazer parte do contexto evolutivo de qualquer pessoa e, dessa forma, diferentes mecanismos podem ser utilizados para o enfrentamento dessa situação.

A vida cotidiana na rua, também, está permeada de eventos violentos e fatores de risco, como pode-se confirmar através do relato de Bianca.

Um dia a gente foi lá na usina da praça, daí a Joana disse que queria entrar para tomar banho daí eu peguei e entrei com ela. Só que tava eu, ela, as gurias, e a Luciana já era uma baita duma guria, nós era bem pequenininha. E a Joana não dava mais pé, só que eu não tinha mais como ajudar ela porque eu também tava quase morrendo, assim também. Depois eu falei 'o Luciana: tu que é maior, ajuda nós aqui, oh Lu, oh Lu', só 
falava assim né, daí ela me olhou para mim e disse 'vocês que sef.', daí eu comecei a gritar: 'ai tadinha da Joana', daí eu pedi ajuda, daí a Vivian puxava a Vanessa, a Vanessa me puxava e eu tentava puxar a Joana, daí quando eu vi a Joana resbalou da minha mão. Ea Luciana tava na frente da Joana, daí a Luciana pego e começou a nadar, não sei como ela consegui não sei é muita sorte e a Luciana pego e saiu dali, e eu pedi para ela me ajudar, pedi para pegar a outra mão da Joana, e a Luciana disse: 'por mim que morra afogada'. Daí quando ela disse isso a mão da guri soltou e ela ficou no rio. Morreu afogada..

Esse evento tornou a menina extremamente vulnerável e exigiu habilidades de enfrentamento que ainda não estavam disponíveis. A partir desse momento, a rua tornou-se o único contexto no qual ela estabeleceu relações significativas com outras pessoas e com as drogas. Estudos apontam o uso de drogas como parte do cotidiano das crianças e adolescentes em situação de rua (Forster, Tannhauser \& Barros, 1996; Neiva-Silva, 2003; Noto \& cols., 2003). A droga passou a cumprir o papel social que permite a inserção e uma identidade grupal. Assume uma função de "poção mágica" capaz de amenizar o sofrimento, a sensação de angústia e abandono, além de proteger da tristeza, fome, frio e dor. Assim, a perda da amiga, a vida na rua, a disponibilidade das drogas, entre outros fatores de risco, promoveram uma maior suscetibilidade e potencializaram os efeitos negativos dessas situações estressantes na trajetória de Bianca “...Eu já usei todas drogas quando tava na rua...”.

Um aspecto crucial na trajetória de Bianca na construção de resiliência frente a todas as adversidades apontadas é a sua vinculação com a escola. Esse microssistema tem sido descrito como potencial protetor para o desenvolvimento humano. De acordo com Hetherington, Bridges e Insabella (1998), as escolas podem atuar como fonte de apoio social pois oferecem ambientes acolhedores e estruturados, os quais proporcionam estabilidade às crianças e aos adolescentes que vivenciam situações adversas em outros contextos. Estes aspectos contribuem para o desenvolvimento de auto-estima e competência social. Independente dos eventos ocorridos em sua vida, a menina não desistiu de freqüentar a escola " $E u$ tô na $8^{\circ}$ série, tia!... Sempre fui à escola. Quero continuar estudando, quero ser advogada”. Este fato é surpreendente quando compreendido frente à realidade das crianças em situação de rua. A literatura aponta um elevado número dessa população que têm ou tiveram experiência escolar (Koller, 1999; Vasconcelos, 1996). No entanto, o espaço ecológico da escola não é atrativo para a maioria dessa população. Embora a escola esteja inserida no contexto desses meninos e meninas a "vinculação" com esse ambiente muitas vezes não é significativa, ou seja, a freqüência é esporádica ou não ocorre (Paludo, 2004). A escola tradicional tem fracassado na recepção desses alunos devido ao preconceito e aos estereótipos oferecidos a esses meninos e meninas que vivem no contexto da rua. O jovem que está na rua dificilmente cumpre os horários estabelecidos pelas instituições escolares, não possui material didático, tem dificuldade em realizar a higiene pessoal diariamente, entre outros percalços cotidianos da vida na rua. No estado do Rio Grande do Sul foram criadas as escolas abertas, com o objetivo de promover o conhecimento acadêmico, respeitando a realidade de vida da criança em situação de rua (Koller, 2001). No caso de Bianca, a manutenção e o desempenho favorável no ambiente escolar refletem o uso de estratégias adequadas frente ao cotidiano desfavorável em que está inserida. Ao mesmo tempo, a sua freqüência à escola garante o sentimento de pertencer a um sistema, afastando-a da exclusão que permeia seu cotidiano. Para Bianca, a escola foi e, ainda, é promotora de resiliência. Esse contexto não ofereceu apenas conhecimento, mas evitou o isolamento social e ampliou as possibilidades para o engajamento em redes de apoio.

Outro mesossistema que incrementa o processo de resiliência de Bianca é a instituição que freqüenta diariamente durante a manhã. Esta Casa de Acolhimento oferece atendimento médico, odontológico, psicológico e social gratuito. Além disso, o contato com os monitores, funcionários e outras crianças e adolescentes proporciona um ambiente saudável permeado de relações afetivas e formando novos microssistemas importantes para o seu desenvolvimento. A partir da inserção ecológica da equipe nessa instituição pode-se perceber a relevância desse ambiente, especialmente, dos funcionários do local para a frequiência da menina ao ambiente. Algumas características institucionais presentes no cotidiano podem ter facilitado ou promovido a vinculação da menina com o ambiente. Entre elas, destacam-se o bom relacionamento entre adultos e crianças, a manutenção de rituais e rotinas, a confrontação pró-ativa dos problemas, a minimização dos conflitos e a ausência de separação e um relacionamento produtivo com as figuras cuidadoras.

No momento, Bianca está frequientando uma outra Casa de Acolhimento que oferece apenas assistência noturna. A sua estada na "rua" é temporária, uma vez que aguarda decisão judiciária sobre em qual instituição será abrigada, uma vez que está sem residência fixa no momento. Ela utiliza todos os serviços oferecidos para meninos e meninas em situação de rua, mas não está vinculada a nenhuma instituição de abrigo. Bianca relata: "Eu durmo lá no acolhimento, mas hoje eu vou na audiência...”. Esse fato explicita a influência do exossistema, o qual envolve ambientes que a pessoa não freqüienta como um participante ativo, mas que desempenham uma influência indireta sobre o seu desenvolvimento (Bronfenbrenner, 1979/1996).

Além das instituições, escola e acolhimentos, Bianca está envolvida com grupos de tratamento para dependência química, devido ao uso abusivo que fazia dessas substâncias. "Já usei de tudo na vida, mas hoje eu sou uma dependente química em recuperação... sou monitora de um grupo, já ajudei vários amigos e o meu namorado a pararem de usar as drogas". A participação em grupos é uma oportunidade para o estabelecimento de redes sociais, possibilitando trocas de experiências com outras pessoas. De acordo com Bronfenbrenner (1979/1996), a participação em vários ambientes proporciona uma oportunidade para o envolvimento da pessoa em novos papéis, atividades e díades. O relacionamento significativo com outra pessoa favorece o desenvolvimento, principalmente quando encorajam a confiança mútua, a orientação positiva e o equilíbrio de poder na relação. A utilização desses recursos oferecidos pela sociedade atua como fonte de apoio social para a adolescente, reduzindo a influência do risco existente no ambiente da rua. As instituições podem proporcionar continência às ansiedades e, 
ao mesmo tempo, exercer a função de fonte de apoio e de oportunidade para que eles expressem seus medos. Essas atitudes possibilitam o fortalecimento e processo de enfrentamento da vida cotidiana, conseqüentemente, incrementando a construção de resiliência.

\section{Reflexões Finais}

Resiliência refere-se ao fenômeno caracterizado por resultados positivos na presença de ameaças ao desenvolvimento das pessoas (Masten, 2001). Toda e qualquer pessoa vivencia algum tipo de dificuldade durante a vida. Certamente a existência humana plenamente feliz e protegida ainda é uma utopia. No entanto, é intrigante perceber que algumas pessoas conseguem enfrentar as situações adversas e outras não. Cabe questionar quais fatores podem favorecer essa habilidade. Rutter (1993) alerta que o importante para compreender a resiliência é tentar conhecer como as características protetoras se desenvolveram e como modificaram o percurso pessoal do indivíduo.

A partir da análise dos fatores de risco e proteção envolvidos no desenvolvimento de Bianca, pode-se afirmar que a luta pela superação de suas experiências negativas na infância e o uso de estratégias estão relacionados com a presença de fatores mediadores, como a rede social de apoio social recebida e a sua capacidade de identificar potencialidade e limitações no cotidiano. Sua fala expressa esse reconhecimento:

Ah, eu sei lá... ah não sei como seria se reencontrasse minha mãe. Não sei se poderia ser diferente ou não. Eu sei lá, eu levo tudo para o outro lado, assim sabe. Eu gosto das tias de lá, sabe bah me dou tri bem assim com elas, só que tem umas tias que são tri chatas assim, daí eu pego e largo lá, mas não que eu não goste de lá sabe, me dou tri bem com as tias, só dessa guria (Luciana) sabe que eu tenho nojo.

Nesse sentido, a presença e a relação com pessoas significativas (monitoras, amiga, mãe) ao longo do desenvolvimento, a rede e a coesão estabelecida nos diferentes contextos (abrigo, rua, escola) parecem ter contribuído favorecendo o processo de resiliência. Além disso, é possível acrescentar as estratégias de superação utilizadas por Bianca. A percepção da mãe idealizada, o estabelecimento de fortes relações de amizade, a busca de atendimento quando em situações de risco permitiram e fortaleceram Bianca na sua incansável busca pelo enfrentamento das adversidades.

A capacidade de afeto e reciprocidade nos relacionamentos interpessoais refletira em processos proximais adequados e eficientes no estabelecimento e estruturação das características da menina. Os contextos dos quais participou, permitem compreender os momentos vividos, as constâncias e as interrupções dos processos desenvolvimentais. E, conseqüentemente, foi possível analisar os processos de resiliência e vulnerabilidade envolvidos. É necessário um novo olhar para as crianças e adolescentes em situação de rua, analisar a vivência da infância, embora permeada de percalços, como um período de construção de subjetividade e significação de experiências.

Crianças e adolescentes em situação de rua, ainda, são percebidos como delinqüentes, marginais e que não possuem expectativas de vida. Essas crenças cristalizam uma imagem estereotipada e impedem o desenvolvimento humano dessa população e, ao mesmo tempo, desacreditam a construção de políticas públicas e intervenções. Essas podem ser compreendidas como macrossistema, o qual é composto pelo padrão global de ideologias, crenças, valores, religiões, formas de governo, culturas e subculturas presentes no cotidiano das pessoas que influenciam seu desenvolvimento (Bronfenbrenner, 1979/1996). No entanto, pesquisas têm demonstrado que os meninos e as meninas que estão em situação de rua estão se desenvolvendo como qualquer outra pessoa (Neiva-Silva, 2003; Paludo, 2004; Santana, 2003; Santos, 2004). Essa população deve ser compreendida sem idéias pré-concebidas, respeitando a sua dinâmica e diversidade, valorizando as suas experiências, expectativas, afetos e valores de cada um. A rua não deve ser percebida, apenas, como uma ameaça ao desenvolvimento dos meninos e meninas que se utilizam dela. É importante e necessário compreender a vivência da rua na sua interação entre risco e saúde. As experiências, as emoções e as habilidades desenvolvidas nesse contexto devem ser valorizadas e analisadas em sua totalidade. Entretanto, é importante destacar que a rua continua sendo um ambiente de risco e potencialmente inadequado para o desenvolvimento de qualquer ser humano. Além disso, os autores evidenciam a possibilidade de construção do processo de resiliência no contexto da rua a partir de uma análise criteriosa dos fatores de risco e proteção. Retomando o conceito de Luthar, Cicchetti e Becker (2000), resiliência pode ser entendida como um processo dinâmico envolvendo adaptação positiva em um contexto de significativa adversidade. Embora o processo de resiliência ainda se contraponha à vivência no contexto da rua, as crianças e os adolescentes que se encontram nessas circunstâncias de vida disponibilizam diversos recursos internos e externos a fim de sobreviver e se desenvolver. Repensar esse fenômeno e suas implicações a partir da abordagem ecológica do desenvolvimento humano implica um novo olhar sobre a realidade daqueles que se encontram em situação de rua. É preciso respeitar os processos de desenvolvimento envolvidos, os fatores de risco e proteção e o momento histórico-temporal no qual estes se inserem. A inserção nesse cenário possibilita reconhecer a potencialidade dos seres humanos em superar as adversidades.

\section{Referências}

Alves, P. B. (2002). Infância, tempo e atividades cotidianas das crianças em situação de rua: As contribuições da teoria dos sistemas ecológicos. Tese de Doutorado, Universidade Federal do Rio Grande do Sul, Porto Alegre.

Alves, P. B. (1998). O brinquedo e as atividades cotidianas de crianças em situação de rua. Dissertação de Mestrado, Universidade Federal do Rio Grande do Sul, Porto Alegre.

Aptekar, L. (1989). Characteristics of street children of Colombia. Child Abuse and Neglect, 133, 427-437.

Bardin, L. (1979). Análise de conteúdo. (L. A. Reto \& A. Pinheiro, Trad.). São Paulo: Edições 70/ Livraria Martins Fontes. (Trabalho original publicado em 1977).

Brito, R. C. (1999). Uso de drogas entre meninos e meninas em situação de rua: Subsídios para uma intervenção comunitária. Dissertação de Mestrado, Universidade Federal do Rio Grande do Sul, Porto Alegre. 
Bronfenbrenner, U. (1995). Developmental ecology throught space and time: A future perspective. Em P. M. Moen, G. H. Elder \& K. Lüscher (Orgs.), Examining lives in context (pp. 619-647). Washington: American Psychological Association.

Bronfenbrenner, U. (1996). A ecologia do desenvolvimento humano: Experimentos naturais e planejados. Porto Alegre: Artes Médicas (Originalmente publicado em 1979).

Bronfenbrenner, U. \& Morris, P. (1998). The ecology of developmental processes. Em W. Damon (Org.), Handbook of child psychology (pp. 993-1027). New York: Jonh Wiley $\&$ Sons.

Bronfenbrenner, U. (1999). Environments in developmental perspective: Theorical and operational models. Em B. Friedman \& T. D. Wacks (Orgs.), Conceptualization and assessment of environments across the life span (pp. 3-30). Washington, DC: American Psychology Association.

Bronfenbrenner, U. (2005). Making human beings human: Biological perspectives on human development. London: Sage Publications.

Cecconello, A. (2003). Resiliência e vulnerabilidade em famílias em situação de risco. Tese de Doutorado, Universidade Federal do Rio Grande do Sul, Porto Alegre.

Conselho Federal de Psicologia (2000). Resolução para pesquisa com seres humanos. Resolução 016/2000, Brasília: CFP.

Cowan, P., Cowan, C. \& Schulz, M. (1996). Thinking about risk and resilience in families. Em E. Hetherington \& E. A. Blechman (Orgs.), Stress, coping and resiliency in children and families (pp.1-38). New Jersey: Lawrence Erlbaum.

D’Abreu, R., Mullis, A. \& Cook, L. (1999). The resilience of street in Brazil. Adolescent, 34, 745-751.

Ferreira, A. (1999). Minidicionário da língua portuguesa. Rio de Janeiro: Nova Fronteira.

Forster, L.; Tannhauser, M. \& Barros, H. (1996). Drug use among street children in southern Brazil. Drug \& Alcohol Dependence, 43, 57-62.

Garmezy, N. \& Masten, A. (1994). Chronic adversities. Em M. Rutter, E. Taylor \& L. Herson (Orgs.), Child and adolescence psychiatry (pp.191-207). Oxford: Blackwell Scientific Publication.

Hetherington, E., Bridges, M. \& Insabella, G. (1998). What matters? What does not? Five perspectives on the association between marital transitions and children's adjustment. American Psychologist, 53, 167-184.

Hutz, C., Koller, S. \& Bandeira, D. (1996). Resiliência e vulnerabilidade em crianças em situação de risco. Coletâneas da ANPEPP, 1(12), 79-86.

Kashani, J. H. \& Allan, W. D. (1998). The impact offamily violence on children and adolescents. Thousand Oaks, CA: Sage.

Koller, S. H. (1999). Violência doméstica: Uma visão ecológica. Em (Org.), Violência doméstica (pp. 32-42). Brasília: Unicef.

Koller, S. (2001). A escola, a rua e a criança em desenvolvimento. Em Z. Del Prette (Org.), Psicologia escolar e educacional: Saúde e qualidade de vida (pp.159-176). Campinas: São Paulo.

Koller, S. H. \& De Antoni, C. (2004).Violência intrafamiliar: Uma visão ecológica. Em S. H. Koller (Org.), Ecologia do desenvolvimento humano: Pesquisa e intervenção no Brasil (pp. 293-310). Porto Alegre: Casa do Psicólogo.

Koller, S. H. \& Hutz, C. S. (1996). Meninos e meninas em situação de rua: dinâmica, diversidade e definição. Coletâneas da ANPEPP: Aplicações da psicologia na melhoria da qualidade de vida, 1, 11-34.
Luthar, S. (1991). Vulnerability and resilience: A study of high risk adolescence. Child Development, 62, 600-616.

Luthar, S., Cicchetti, D. \& Becker, B. (2000). The construct of resilience: A critical evaluation an guidelines for future work. Child Development, 71(3), 543-562.

Masten, A. (2001). Ordinary magic: Resilience process in development. American Psychologist, 56, 227-238.

Masten, A. \& Garmezy, N. (1985). Risk, vulnerability and protective factors in developmental psychopathology. Em B. B. Lahey \& A. E. Kazdin (Orgs.), Advances in clinical child psychology (pp.1-52). New York: Plenum.

Ministério da Saúde/CNS (1996). Resolução no 196/96 Diretrizes e normas regulamentadoras de pesquisas envolvendo seres humanos. Brasília: Ministério da Saúde.

Mitchell, J. (2001). The influence of father abandonment. The Sciences and Engineering, 62(1), 578.

Neiva-Silva, L. (2003). Expectativas futuras de adolescentes em situação de rua: um estudo autofotográfico. Dissertação de Mestrado, Universidade Federal do Rio Grande do Sul, Porto Alegre.

Neiva-Silva, L. \& Koller, S. H. (2002). A rua como contexto de desenvolvimento. Em E. R. Lordelo, A. M. A. Carvalho \& S. H. Koller (Orgs.), Infância brasileira e contextos de desenvolvimento (pp. 202-230). São Paulo, SP: Casa do Psicólogo, Salvador, BA: Editora da Universidade Federal da Bahia.

Noto, A. R., Galduróz, J. C. F., Nappo, S. A., Fonseca, A., Carlini, C., Moura, Y. \& Carlini, E. (2003). Levantamento nacional sobre o uso de drogas entre crianças e adolescentes em situação de rua nas 27 capitais brasileiras - 2003. Centro de Informações sobre Drogas Psicotrópicas. Universidade Federal de São Paulo.

Paludo, S. (2004). Expressão das emoções morais de crianças em situação de rua. Dissertação de Mestrado, Universidade Federal do Rio Grande do Sul, Porto Alegre.

Paludo, S. \& Koller, S. (2004). Inserção ecológica no contexto da rua. Em S. H. Koller (Org.), Ecologia do desenvolvimento humano: Pesquisa e intervenção no Brasil (pp. 219-244). Porto Alegre: Casa do Psicólogo.

Roig, A. \& Ochtorena, J. (1993). Maltrato y abandono en la infancia. Barcelona: Ediciones Martinez Roca.

Rutter, M. (1987). Psychosocial resilience and protective mechanisms. American Journal of Orthopsychiatry, 57, 316331.

Rutter, M. (1993). Resilience: Some conceptual considerations. Journal of Adolescence Health, 14, 626-631.

Rutter, M. (1996). Psychosocial resilience and protective mechanisms. Em J. Rolf, A. Masten, D. Cicchetti, K. Nuechterlein \& S. Weintraub (Orgs.), Risk and protective factors in the development of psychopathology (pp.181-214). New York: Cambridge University.

Santana, J. (2003). Instituições de atendimento à crianças em situação de rua: A relação entre os objetivos e significados atribuídos por seus dirigentes e pelas crianças atendidas. Dissertação de Mestrado, Universidade Federal do Rio Grande do Sul, Porto Alegre.

Santos, C. (2004). O que leva uma mãe a abandonar um filho? Dissertação de Mestrado, Universidade Federal do Paraná, Curitiba.

Swart-Kruger, J. \& Donald, D. (1996). Crianças das ruas da África do Sul. Psicologia: Reflexão e Crítica, 9(1), 59-82. 
Vasconcelos, M. (1996). Família, trabalho e drogas: Estudo exploratório da representação dos meninos de rua da cidade de João Pessoa sobre as suas condições de vida. Dissertação de Mestrado, Universidade Federal da Paraíba, João Pessoa.

Weber, L. (2000). Filhos de ninguém. Conjuntura social: Crianças e jovens, 4, 30-36.

Weber, L. \& Gagno, A. (1995). Onde estão os vínculos das crianças institucionalizadas? Trabalho apresentado no X Congresso Latino Americano de Psiquiatria da Infância e Adolescência, Curitiba.

Werner, E. \& Smith, R. (1992). Overcoming the odds: High risk children form birth to adulthood. London: Cornell University.

Zimmerman, M. \& Arunkumar, R. (1994). Resiliency research: Implications for schools and policy. Social Policy Report, 8, $1-18$.
Yunes, M. (2003). Psicologia positiva e resiliência: O foco no indivíduo e na família. Psicologia em Estudo, 8(número especial), 75-84.

Yunes, M. (2001). A questão triplamente controvertida da resiliência em famílias de baixa renda. Tese de Doutorado, Pontificia Universidade Católica de São Paulo, São Paulo.

Recebido em 25.11.2004

Primeira decisão editorial em 04.04.2005

Versão final em 13.05.2005

Aceito em 26.07.2005 